\title{
Theoretical study of the vibrational excitation of $\mathrm{SO}\left(\mathrm{B}^{3} \Sigma^{-}\right)$molecules by collisions with Ar atoms
}

\author{
Ramon S. da Silva and Maikel Y. Ballester \\ Departamento de Física, Universidade Federal de Juiz de Fora, Juiz de Fora, MG, Brasil \\ Juiz de Fora, MG, Brasil \\ ramonshowsa@gmail.com
}

\begin{abstract}
The methodology of quasi-classical trajectories $(Q C T)$ is used to investigate how occurs the energy transfer (ET) processes in collisions involving $\mathrm{SO}\left(\mathrm{B}^{3} \Sigma^{-}\right)$molecules and $\mathrm{Ar}\left({ }^{1} \mathrm{~S}\right)$ atoms. Particularly, transfers of the type translation-to-vibration $(T-V)$ are the main focus of this work. In order to achieve this goal, a new potential energy surface (PES) was developed based on the pairwise addition. Such methodology has been widely used within the double many-body expansion (DMBE). Topological features of PES for the the triatomic system are discussed. Our results from the molecular dynamics, point out that $T$-V excitation processes present a barrier type behavior. This suggests that, in this case, repulsive interactions between sulfur monoxide and argon atom play a key role.
\end{abstract}

\section{Introduction}

The study of weakly bounded molecular complexes of rare gas atoms with $\mathrm{S}$ containing molecules have been the focus of many experimental and theoretical studies [1, 2, 3, 4]. The weakly bounded species or molecular aggregates often are referred as van der Waals (vdW) complexes. As has pointed out in the previous literature, the accurate description of $\mathrm{vdW}$ species is essential not only to supply information about intermolecular forces but also reactive collisions, pressure dependence, energy transfer (ET) processes, combustion, and interstellar chemistry studies [1, 2, 3, 4, 5]. In the present work, we are interested to investigate $\mathrm{Ar} \cdots \mathrm{SO}$ vdW specie in a electronic excited state.

Experimentally, Hatano and coworkers studied the quenching and vibrational relaxation of of $\mathrm{SO}\left(\mathrm{B}^{3} \Sigma^{-}\right)$ through collisions with $\mathrm{Ar}$ atoms and $\mathrm{N}_{2}$ molecules. As results, they report rate coefficients for some vibrational levels [3]. In the same way, Yamasaki et al. report the radiative lifetimes and deactivation rate constants of $\mathrm{SO}\left(\mathrm{B}^{3} \Sigma^{-}, v^{\prime}=\right.$ 0,1 , and 2) by collisions with $\mathrm{He}$ [5]. However, to best of our knowledge, there is not theoretical work considering only the translation-to-vibration (T-V) energy transfer (ET) processes on the following process

$$
\mathrm{Ar}+\mathrm{SO}\left(\mathrm{B}^{3} \Sigma^{-}, v=0\right) \rightarrow \mathrm{Ar}+\mathrm{SO}\left(\mathrm{B}^{3} \Sigma^{-}, v^{\prime}\right)
$$




\section{Blucher Proceedings X Encontro Científico de Física Aplicada Blucher}

In this inelastic collision, the translationally hot (or hyperthermal) Ar atoms transfer part of its kinetic energy to internal energy of the diatomic molecules target. According to Smith et al. the ET processes represent an important physical chemical phenomenon and, therefore, require attention [6].

Motivated by these informations, the vibrational excitation of $\mathrm{SO}\left(\mathrm{B}^{3} \Sigma^{-}\right)$ molecules produced by collisions with $\operatorname{Ar}\left({ }^{1} S\right)$ is investigated. To achieve our goal, firstly, a three-dimensional analitycal potential energy surface (PES) is proposed to describe the interaction energies in a function of internuclear distances. To perform molecular dynamical calculations, the quasi-classical trajectory (QCT) method was adopted.

The article is structured as follows: Section 2 describes the analytic representation of the Ar..SO vdW specie in a electronic excited state as well as its main atributtes. While the QCT calculations are gathered in Section 3, Our results are discussed in Section 4 and the concluding remarks are given in the last section.

\section{PES representation}

Within the framework of double many-body expansion (DMBE) theory [4, 7], the analytical representation of the potential energy surface for the excited electronic state of Ar...SO, assuming the pairwise addition, can be written as:

$$
\begin{aligned}
\mathrm{V}_{\mathrm{Ar} \ldots \mathrm{SO}}(\mathbf{R}) & =\mathrm{V}_{\mathrm{SO}}\left(\mathrm{R}_{\mathrm{SO}}\right)+\mathrm{V}_{\mathrm{ArS}}\left(\mathrm{R}_{\mathrm{ArS}}\right) \\
& +\mathrm{V}_{\mathrm{ArO}}\left(\mathrm{R}_{\mathrm{ArO}}\right)
\end{aligned}
$$

where $\mathbf{R}$ represents the set of all the three internuclear distances defining the molecular configuration.
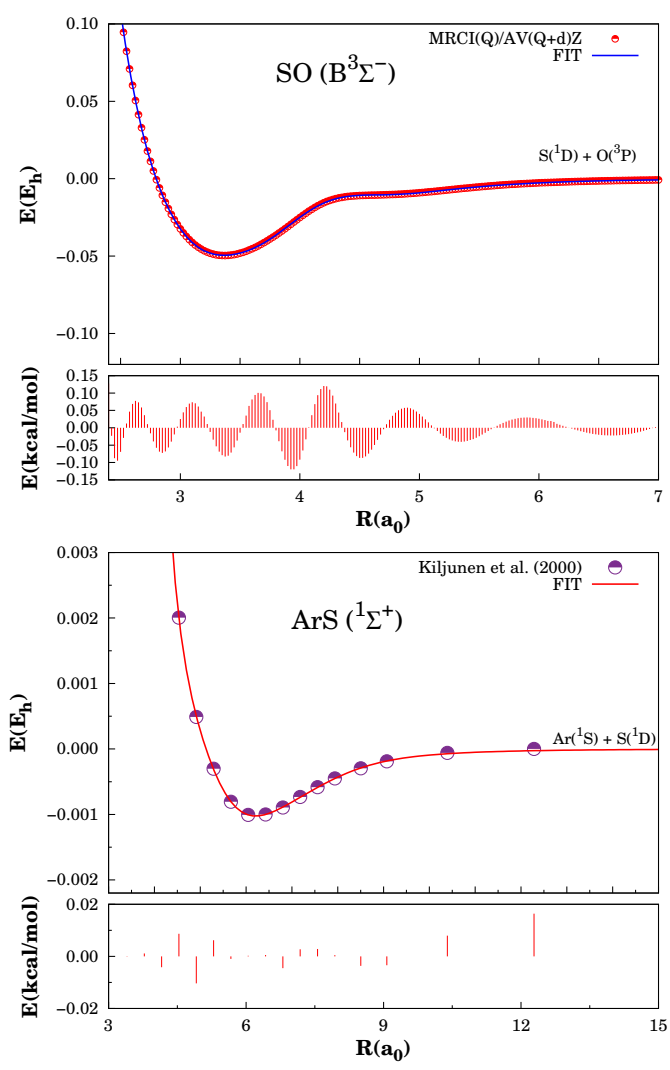

Figure 1: Potential energy curves for diatomic molecules: $\operatorname{ArS}\left({ }^{1} \Sigma^{+}\right)$(Bottom panel) and $\mathrm{SO}\left(\mathrm{B}^{3} \Sigma^{-}\right)$(Top panel).

The physically appropriate behavior at asymptotic limits are warranted using Extended Hartree-Fock Approximate Correlation Energy (EHFACE) model [7]. Yet, more details from these expansion are found in Refs. [4, 7, 8] (see also references therein) and, therefore, will not be repeated here. The analytical potential energy curve (APEC) for fragment ArO $\left({ }^{3} \Pi\right)$ was extracted from the Ref.[8]. The parameters for the potential interaction between the argon atom and sulfur, given by $\mathrm{V}_{\mathrm{ArS}}$, were obtained by fitting $a b$ initio electronic energies reported by Kiljunen et al. [9]. There, the excited state for $\operatorname{ArS}\left({ }^{1} \Sigma^{+}\right)$molecule dissociate in $\operatorname{Ar}\left({ }^{1} S\right)+S\left({ }^{1} D\right)$ was computed at the multireference configuration interaction (MRCI) level including Davidson 


\section{Blucher Proceedings X Encontro Científico de Física Aplicada Blucher}

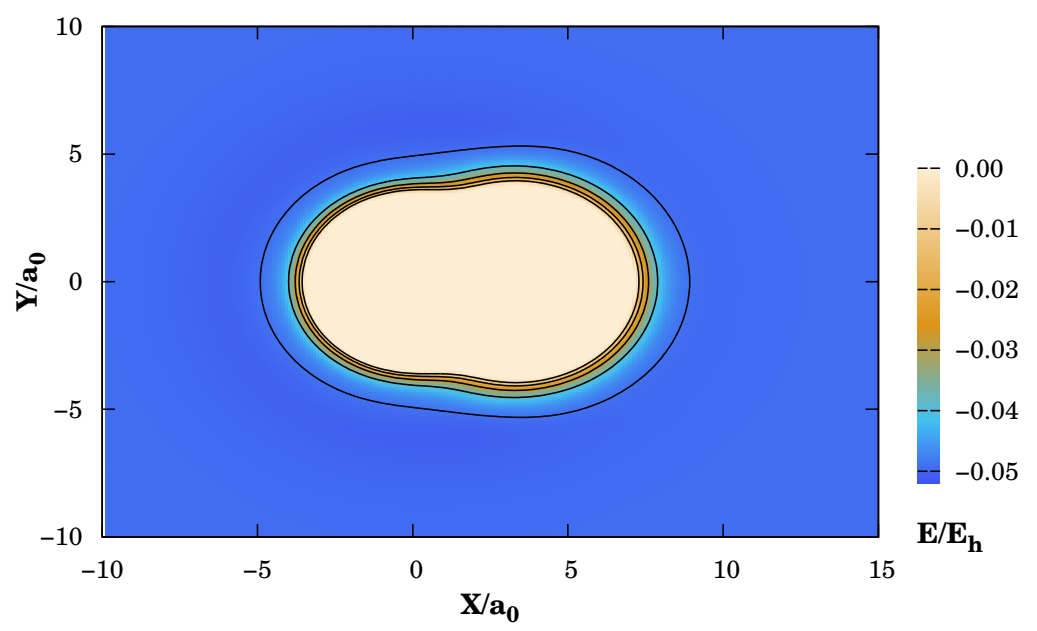

Figure 2: Contours plot of potential energy surface for a Ar atom moving coplanarly around a partially relaxed $\mathrm{SO}\left(\mathrm{B}^{3} \Sigma^{-}\right)$molecule with the center of mass fixed at the origin.

correction (MRCI+Q) using the Full Valence Complete Active Space-Self Consistent Field (CASSCF) wave function as the reference. AVQZ Dunning basis set has been employed and combined with ten electron-core pseudo-potential basis set so-called MRCI+Q/AVQZ-Stutt [9].

To study the diatomic fragment $\mathrm{SO}\left(\mathrm{B}^{3} \Sigma^{-}\right)$, ab initio calculations have been carried out at MRCI+Q level using CASSCF wave functions in combination with aug-cc-pvQz $(A V(Q+d) Z)$ basis set of Dunning [10]. The impact of the additional tight $\mathrm{d}$ functions in the S-bearing molecules has been shown be very significative. All the calculations are made with the MOLPRO package [11]. Figure 1 depicts the APEC calculated for the $\operatorname{ArS}\left({ }^{1} \Sigma^{+}\right)$(Bottom panel) and $\mathrm{SO}\left(\mathrm{B}^{3} \Sigma^{-}\right)$ (Top panel) diatomic molecules. The differences between our fits and the $a b$ initio points are also included. As can be seen, our fits present differences less than $0.02 \mathrm{kcal} / \mathrm{mol}$ for $\mathrm{ArS}$ and $0.15 \mathrm{kcal} / \mathrm{mol}$ for SO.

\section{QCT calculations}

All dynamics calculations here reported have utilized the QCT method as implemented in VENUS96 program [12] and the DMBE PES presented in the previous section. Such methodology has been extensively applied to others systems [4, 8, 13]. In the present work, relative translational energies were selected covering the range $10 \leq \mathrm{E}_{\mathrm{tr}} / \mathrm{kcal}$. $\mathrm{mol}^{-1} \leq 100$. As $\mathrm{T}-\mathrm{V}$ collisional ET is characterized by inelastic scattering, here, we focused in the non-reactive trajectories producing a vibrationally excited $\mathrm{SO}\left(\mathrm{B}^{3} \Sigma^{-}\right)$. For each collisional energy, the initial vibrational and rotational quantum numbers of the sulfur monoxide molecules targets have been fixed at the ground level $\left(\mathrm{j}_{\mathrm{SO}}=0, v_{\mathrm{SO}}=0\right)$.

The time integration step was fixed to $2.5 \times 10^{-16}$ s ensuring total energy and angular momentum conservation. Collision partners were initially separated by a distance $15 \AA$, which is sufficiently long to leave atom-diatom interaction ini- 


\section{Blucher Proceedings X Encontro Científico de Física Aplicada Blucher}

tially negligible. The next step in trajectory calculations was to define the maximum value of the impact parameter $\left(b_{\max }\right)$. Specially, in these first analysis we fix $b_{\max }=5.0 \AA$. This value has been demonstrated to be sufficient for our purposes.

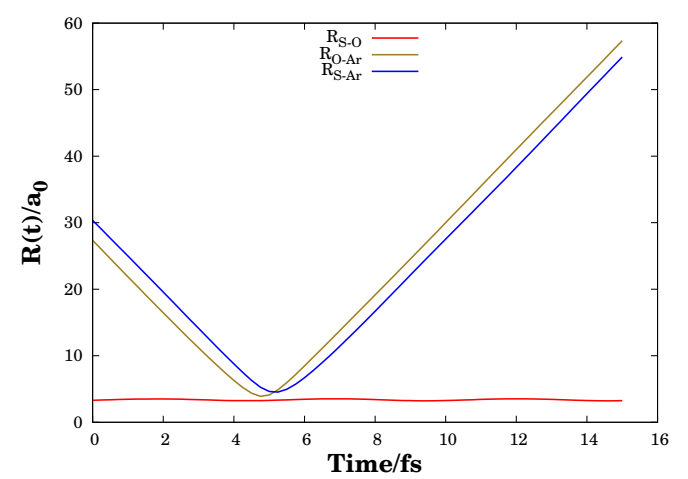

Figure 3: Distance vs time plot for a typical trajectory of the reaction $\mathrm{Ar}+\mathrm{SO}\left(\mathrm{B}^{3} \Sigma^{-}, v=\right.$ $0) \rightarrow \mathrm{Ar}+\mathrm{SO}\left(\mathrm{B}^{3} \Sigma^{-}, v^{\prime}\right)$. The trajectory corresponds to a relative translational energy of $50 \mathrm{kcal} / \mathrm{mol}$.

\section{Results}

We start this discussion showing the spectroscopic parameters $R_{e}, D_{e}$, and $w_{e}$ of both $\mathrm{SO}\left(\mathrm{B}^{3} \Sigma^{-}\right)$and $\operatorname{ArS}\left({ }^{1} \Sigma^{+}\right)$diatomic species. For comparison, also gathered in this same table are the results experimental and other theoretical [14, 15]. All our results presented show good agreement with other works.

Once obtained an analytical representation for interaction potential of Ar...SO system, we thus investigated its topological features. A diagram showing contour plots for $\mathrm{Ar}$ atom moving coplanarly around a partially relaxed $\mathrm{SO}\left(\mathrm{B}^{3} \Sigma^{-}\right)$molecule is depicted in Fig. 2 . Analyzing this figure, it is seen that the analytical proposal for three-dimensional PES of Ar ‥SO system, smoothly describes interactions on the repulsive part of the potential when Ar approaching to the sulfur monoxide molecule.

For this van der Waals system, the value of global minimum of the interaction energy is $-0.0506 \quad \mathrm{E}_{\mathrm{h}}$ $(-31.75 \mathrm{kcal} / \mathrm{mol})$. The difference between well depths at equilibrium of the excited $\mathrm{Ar} \cdots \mathrm{SO}$ van der Waals molecule and the well depth of $\mathrm{SO}\left(\mathrm{B}^{3} \Sigma^{-}\right)$is 0.0013 $\mathrm{E}_{\mathrm{h}}(0.81 \mathrm{kcal} / \mathrm{mol})$. The $\mathrm{vdW}$ structure predicted by the our calculations shows that the bond lenghts are $\mathrm{r}_{\mathrm{e}}(\mathrm{SO})=3.3740$ $\mathrm{a}_{0}, \mathrm{r}_{\mathrm{e}}(\mathrm{ArS})=6.7035 \mathrm{a}_{0}$, and $\mathrm{r}_{\mathrm{e}}(\mathrm{ArO})=$ $6.6292 \mathrm{a}_{0}$. The vibrational harmonic frequencies obtained in this work are $\omega_{1}=$ $67.59 \mathrm{~cm}^{-1}, \omega_{2}=638.67 \mathrm{~cm}^{-1}$, and $\omega_{3}$ $=31.43 \mathrm{~cm}^{-1}$. To the best of our knowledge, there are not experimental or theoretical data to compare with these.

To finish, Fig. 3 displays a typical non-reactive trajectory involved in a $\mathrm{T}-\mathrm{V}$ ET process to illustrate the nature of the motion and changes in energy throughout the collision. There, a short encounter (less than $1 \mathrm{fs}$ ) between the reactants and fast separation of the products is visualized.

\section{Final Remarks}

We have reported a new PES for ArSO system based on pairwise addition. The properties of global minimum such as geometry, energy and vibrational frequencies are shown together with other topological features. A vibrational excitation of $\mathrm{SO}\left(\mathrm{B}^{3} \Sigma^{-}\right)$reactant was explored by means of a QCT molecular dynamic approach. We want to highlight that, in relation to vibrational relaxation of of $\mathrm{SO}\left(\mathrm{B}^{3} \Sigma^{-}\right)$, a detailed analysis is being preparation. 


\section{Blucher Proceedings \\ X Encontro Científico de Física Aplicada Blucher}

Table 1: Equilibrium bond length $R_{e}$ (in $\AA$ ), vibrational constant $\omega_{e}$ (in $\mathrm{cm}^{-1}$ ), and the well depth $D_{e}$ (in $\mathrm{E}_{\mathrm{h}}$ ) for the interaction potentials correponding to diatomic fragments. Theoretical and experimental data are also listed.

\begin{tabular}{ccccc}
\hline \hline Molecule & Source & $R_{e}$ & $\omega_{e}$ & $D_{e}$ \\
\hline $\mathrm{SO}\left(\mathrm{B}^{3} \Sigma^{-}\right)$ & This work & 3.3739 & 638.7 & 0.0493 \\
& Exp. [14] & 3.3542 & 630.4 & 0.0518 \\
& Theo. [14] & 3.3674 & 631.7 & 0.0509 \\
& & & & \\
$\operatorname{ArS}\left({ }^{1} \Sigma^{+}\right)$ & This work & 6.2080 & 41.0 & 0.0010 \\
& Theo. [15] & 7.1053 & - & 0.0007 \\
& & & & \\
$\operatorname{ArO}\left({ }^{1} \Sigma^{+}\right)$ & This work & 6.6291 & 33.08 & 0.0002 \\
\hline \hline
\end{tabular}

\section{Acknowledgments}

Authors Acknowledge the financial support from CAPES - Finance Code 001.

\section{References}

[1] AQUILANTI, V. et al., J. Phys. Chem. A, v. 101, p. 6523-6527, 1997.

[2] LIQUE, F. et al., J. Chem. Phys., v. 126, p. 164312, 2007.

[3] HATANO, T. et al., J. Phys. Chem. A, v. 111, p. 1200-1206, 2007.

[4] DA SILVA, R.S. and BALLESTER, M. Y., J. Chem. Phys., v. 149, 144309, 2018.

[5] YAMASAKI, K. et al., J. Phys. Chem. A, v. 107, p. 2442-2447, 2003.

[6] SMITH, J.M. et al., J. Am. Chem. Soc., v. 136, p. 1682-1685, 2014.

[7] VARANDAS, A.J.C. Adv. Chem. Phys, v. 74, p. 255-338, 1988. VARANDAS, A.J.C; DA SILVA,
J.D., J. Chem. Soc., Faraday Trans., v. 88, p. 941-954, 1992.

[8] MARQUES, J.M.C. et al., J. Phys. Chem., v. 100, p. 17513-17522, 1996.

[9] KILJUNEN, T. et al., J. Chem. Phys., v. 112, p. 7475-7483, 2000.

[10] DUNNING JR, T.H. et al., J. Chem. Phys., v. 114, p. 9244-9253, 2001.

[11] WERNER, H-J, et al. MOLPRO (2012), a package of ab initio programs. See http://www. molpro. net

[12] HASE, W.L. et al., QCPEBull.16, 43 (1996)

[13] DA SILVA, R.S.; GARRIDO, J.D.; BALLESTER, M.Y., J. Chem. Phys., v. 147, p. 084308, 2017.

[14] YU, L.; BIAN, W.J., Comput. Chem., v. 32, p. 1577-1588, 2011 and references therein.

[15] LARA, M. et al., Phys. Chem. Chem. Phys., v. 19, p. 28555-28571, 2017. 